\title{
LISTA PRELIMINAR DE RÉPTEIS DA ESTAÇÃO ECOLÓGICA DO TAIM, RIO GRANDE DO SUL
}

NORMA GOMES

LIGIA KRAUSE:

\section{ABSTRACT}

Reptiles were collected during a period of two years in the Estação Ecológica do Taim, in the southeastern part of the state of Rio Grande do Sul, in a region characterized by large extensions of swamps, sand dunes and prairies.

Out of 81 species of reptiles known from the State 21 have been collected in the station. Freshwater turtles are most abundant; others groups are poorly represented.

\section{INTRODUÇÃO}

A área da Estação Ecológica do Taim, desde sua criação em 1978, pelo plano de implantação de Reservas Ecológicas, vem sendo objeto de um amplo plano de pesquisas, coordenado pelo Núcleo Interdepartamental de Ecologia da Universidade Federal do Rio Grande do Sul (NIDECO). No projeto de levantamento faunístico, coube-nos o estudo da herpetofauna, iniciado em janeiro de 1979, para reconhecimento das espécies e organização de uma coleção de referência. Com base neste levantamento preliminar, serão elaborados planos específicos de pesquisa.

Após dois anos de trabalhos na região, publicamos a primeira lista de ocorrência de répteis, ressaltando que será possivelmente ampliada.

\section{DESCRIÇÃO DA AREA}

A Estação Ecológica do Taim, na porção sul da faixa litorânea do Estado do Rio Grande do Sul, entre a lagoa Mirim e o Oceano Atlântico, a 32 $50^{\prime}$ S e $52^{\circ} 26^{\prime} \mathrm{W}$, tem uma extensão de $330 \mathrm{~km}^{2}$. A área compreende o grande banhado do Taim, extensas regiões de dunas, parte da margem leste da lagoa Mirim, porção norte da lagoa Mangueira, as lagoas Nicola e Jacaré, campos e capões de mata.

A maior parte da área é ocupada pelo banhado do Taim, constituído de grandes porções alagadiças cobertas por vegetação densa e quase uniforme, composta principalmente por espadana - Zizianopsis bonariensis (Gramineae) - e junco do banhado ou tiririca - Scirpus californicus (Cyperaceae). Na borda do banhado, em lugares um pouco mais elevados, a vegetação é arbustiva, bastante cerrada, sendo comum a corticeira - Erythrina crista-galli (Leguminosae) - árvore de maior porte.

A região de banhado varia segundo as estações do ano; durante as épocas de chuva torna-se totalmente alagada, sendo praticamente inacessível; no verão, com as chuvas menos intensas, as porções alagadas ficam mais restritas, ocorrendo também uma expansão da vegetação de suas bordas.

$\mathrm{Na}$ grande extensão da área coberta por areia são encontrados dois tipos de dunas: 1) o alinhamento de dunas litorâneas, situado entre as porções leste do banhado do Taim e da lagoa Mangueira, bastante elevadas e móveis, que se deslocam facilmente, recobrindo consideráveis áreas na região dos campos. Por este caráter de mobilidade é rara a fixação de vegetação. A vegetação é constituída de Androtrychum trigynum (Cyperaceae) - junco da areia, que ocorre nas porções mais baixas, de forma isolada, em pequenas moitas ou recobrindo uma ceria extensão de areia; 2) dunas mais baixas e fixas da

1. Museu de Zoologia, Universidade de São Paulo.

2. Departamento de Zoologia, Instituto de Biociências, Universidade Federal do R:o Grande do Sul. 


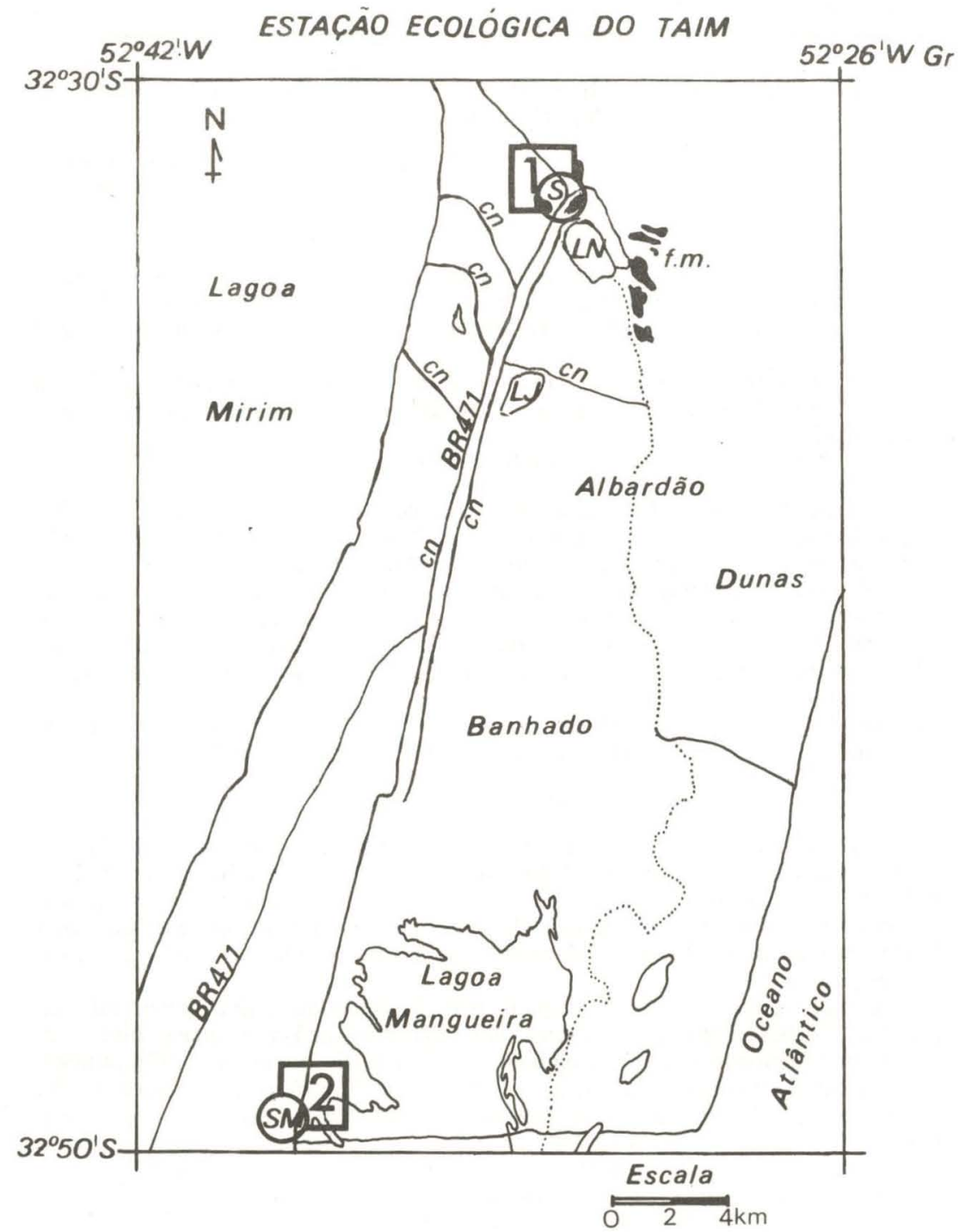

Fig. 1. Mapa da área da Estação Ecológica do Taim, RS.

1. Sede da Fazenda Caçapava, 1a - Margem do banhado, 1b - Dunas próximas ao banhado, $1 \mathrm{c}$ - Alinhamento de dunas litorâneas; 2a - Mata à frente da sede da Estação, 2b - Matas ciliares atrás da sede, 2c - Matas da área de Albardão; 3. Fazenda Sta. Marta; 4. Margem leste da lagoa Mirim, 4a - Dunas da lagoa Mirim, 4b - Matas ciliares da margem da lagoa Mirim; 5a - Campos em volta a sede da Estação, 5b - Campos da área de Albardão. CN - Canais; LJ - Lagoa do Jacaré; LN - Lagoa do Nicola; $\mathrm{S}$ - Sede da Estação. Em linha pontilhada o limite aproximado do alinhamento das dunas litorâneas. 
margem da lagoa Mirim, que podem ser parcialmente recobertas por uma vegetação baixa e espinhosa, composta principalmente por Indigofera sabulicola (Leguminosae), Chenopodium ambrosioides (Chenopodiaceae) e Smilax campestris (Liliaceae).

Os campos são quase totalmente planos, com apenas pequenas colinas arredondadas, próximas à margem da lagoa Mirim. A região de campos se estende ao norte do banhado do Taim, recoberta por gramíneas rasteiras formando pastagens naturais. Os campos não apresentam fisionomia constante durante o correr do ano, sendo cobertos por areia trazida pelo vento ou alagados pela subida do nível das águas.

Os capões de mata são bastante reduzidos. O maior sítio de mata, localizado à frente da sede da Estação, tem árvores de grande porte como as figueiras - Ficus subtriplinervia (Moraceae), grande número de cactáceas, sendo o chão coberto por gramíneas. Este local encontra-se bastante desfigurado pela presença, durante anos, de gado; é também área inundável em alguns períodos do ano.

Outras áreas de restos de mata se encontram atrás da sede da Estação, estendendo-se de modo descontínuo até a lagoa Mirim; finalmente, são encontrados capões de mata na área de Albardão. Em geral, nos bordos destes capões há gravatás - Eryngium pandanifolium (Umbelliferae) e grande quantidade de banana do mato - Bromelia antiacantha (Bromeliaceae).

\section{METODO}

A diversidade de ambientes levou-nos a estabelecer sítios preferenciais de coleta, onde esses ambientes estivessem bem representados. A escolha foi feita durante nossa primeira viagem à Estação, após um reconhecimento geral da região (Fig. 1).

1) Porção leste do grande banhado do Taim. A base para este sítio é a Fazenda Caçapava, situada entre o banhado e o mar; aí estabelecemos três pontos de coleta:

a. Margem do banhado até onde é possível penetrar

b. Dunas próximas ao banhado

c. Alinhamento de dunas litorâneas onde há vegetação.

2) Área de restos de mata. Também três pontos de coleta:

a. A pequena mata situada à frente da Estação, ao norte do banhado do Taim.

b. Capões de mata atrás da sede da Estação.

c. Capões de mata da área de Albardão.

3) Fazenda Santa Maria, ao sul do banhado, na margem oeste da lagoa Mangueira.

4) Margem leste da lagoa Mirim, a mais ou menos $1 \mathrm{~km}$ ao sul da Vila do Taim. Dois locais de coleta:

a. Dunas cobertas por vegetação.

b. Início dos pequenos capões de mata.

5) Campos. Escolhemos duas áreas:

a. Campos situados ao redor da sede da Estação, que em direção oeste, cortados por capões de mata e por Fazendas, estendem-se até as margens da lagoa Mirim.

b. Campos da área de Albardão.

Depois de nossa primeira viagem de reconhecimento foram marcadas coletas, preferencialmente, nos meses quentes do ano; numa segunda etapa começamos viagens mensais.

Os locais de coleta são percorridos com o máximo de atenção para localização e apreensão de animais. As coletas em geral são manuais. Para tartarugas utilizamos pequenas redes (puçás) ou covos colocados à saída dos canais; para os lagartos grandes redes grosseiras construídas com tecido resistente; algumas vezes foram usadas armadilhas com iscas. 
Testudines - Fam. Chelidae

Hydromedusa tectifera (Cope, 1869) - canal próximo à sede da Estação, iv e xii. 1979, xi. 1980; Fazenda Santa Marta, i. 1980; Vila do Taim, i. 1980. Phrynops hilarii (Dumeril \& Bibron, 1835) - próximo ao mar entre a área de Albardão e a Fazenda Caçapava, i. 1979; Lagoa Jacaré (jovem, adulto e ovos), iv. 1979.

Platemys spixii (Dumeril \& Bibron, 1835) - campos da sede da Estação, i, iv, xi. 1979; estrada para a cidade de Rio Grande, iv. 1979.

Fam. Emydidae:

Chrysemys dorbigni (Dumeril \& Bibron, 1835) - canal próximo à sede, xi. 1979; campos da sede da Estação, xi. 1979; i. 1980; Fazenda Caçapava, xii. 1979; lagoa Jacaré, iv. 1979.

Os quelônios são encontrados em todos os corpos de água presentes na região, desde pequenos lençóis aprisionados nos terrenos mais baixos, nos canais que circundam o banhado ou de interligação de lagoas, até nas grandes massas de água.

Essas tartarugas de água doce são vistas tomando sol à margem das massas de água, por vezes nadando na superfície com a cabeça acima do nível da água ou caminhando no campo ou na areia nos períodos de oviposição.

Observamos que a incidência de Chrysemys e Phrynops é bem maior do que a de outros gêneros. Apesar de termos encontrado um exemplar recémnascido de Phrynops hilarii em 22 de abril, um ovo de Platemys spixii em 22 de abril que eclodiu no dia seguinte, só conseguimos determinar com exatidão os sítios de oviposição e a época em que ocorre para Chrysemys dorbigni.

A coleta na água, além da que é feita com redes manuais e covos, também ocorre ao acaso quando as tartarugas caem nas redes dos pescadores. Em terra, a coleta é feita manualmente, sem nenhuma resistência; quando as tartarugas são surpreendidas na construção dos ninhos ficam totalmente imóveis.

Sauria - Fam. Iguanidae

Liolaemus occipitalis Boulenger, 1885 - alinhamento de dunas litorâneas, xii. 1979; dunas próximas ao banhado na Fazenda Caçapava, xii. 1979, xii. 1980.

Fam. Teiidae

Pantodactylus s. schereibersii Wiegmann, 1834 - campos da sede da Estação, iii, x, xi. 1980, ii. 1981.

Tupinambis sp. - Fazenda Santa Marta, i. 1979, i. 1980; mata à frente da sede da Estação, xi. 1979; capões de mata atrás da sede, xii. 1979; Fazenda Caçapava, xii. 1979; Vila do Taim, i. 1980; campos da sede da Estação, i, xi, xii. 1980, ii. 1981; dunas próximas à lagoa Mirim, xii. 1980.

Em revisão do gênero Tupinambis, Presch (1973) propõe o nome de rufescens para a espécie que ocorre ao Sul da América do Sul. Contudo o material procedente da região estudada não coincide com os caracteres apresentados para tal espécie.

Dentre as sete espécies da família Iguanidae citadas como ocorrendo no Rio Grande do Sul, apenas Liolaemus occipitalis foi encontrado na região do Taim.

Esses pequenos lagartos são vistos sobre a areia cruzando o espaço entre as moitas de Androtrychum trigynum. Quando perseguidos, fogem para uma das moitas e se enterram na areia, ficando totalmente encobertos por ela, mas quase à sua superfície. 
A família Teiidae é bem representada na região do Taim; dos quatro gêneros assinalados para o Rio Grande do Sul apenas Cnemidophorus não foi coletado na área.

Os espécimes de Pantodactylus foram encontrados sob canos e caibros de madeira em ambiente úmido e com pouca luminosidade; esses pequenos lagartos de coloração marrom-escura são bastante ágeis e rápidos.

Teius teyou Daudin 1802, foi visto apenas uma vez (não foi possível coletá-lo) sobre as dunas, na porção recoberta por vegetação espinhosa, próxima à margem da lagoa Mirim.

Os grandes exemplares de Tupinambis são os mais abundantes entre os que ocorrem na região; foram encontrados nos diversos pontos que delimitamos para coleta. No limite sul da Estação, entre o alinhamento de dunas litorâneas e a lagoa Mangueira, há porções alagadas; numa de nossas coletas surpreendemos um desses grandes lagartos, que fugiu, mergulhando na água, permanecendo longo tempo no fundo.

Nos capões de mata, quando perseguidos, desenvolvem uma grande velocidade até atingir um abrigo seguro, em geral entre as moitas de bromélias. Nas dunas cobertas de vegetação na margem da lagoa Mirim obtivemos um exemplar jovem em armadilha com isca feita de sebo, amendoim e carne.

Amphisbaenia - Fam. Amphisbaenidae

Amphisbaena darwinii trachura Cope 1885 - mata em frente à sede da Estação, ix. 1980, iii. 1981, em toca de roedor Ctenomys torquatus (Tuco-tuco). Exemplares de Amphisbaena darwinii trachura são raros nesta região.

Serpentes - Fam. Colubridae

Dromicus poecilogyrus (Wied, 1825) - Fazenda Santa Marta, iv. 1979; Fazenda de Caçapava, xi. 1979.

Elapomorphus bilineatus (Dumeril, Bibron \& Dumeril, 1854) - Campos da sede da Estação, xii. 1979.

Helicops carinicauda (Wied, 1825) - Campos da sede da Estação, iii, iv. 1979; i. 1980 ; i. 1981.

Liophis anomalys (L., 1758) - Campos da sede da Estação, xi. 1979; Fazenda Caçapava, xi. 1979; estrada para a cidade de Rio Grande, iv. 1979. Liophis jaegeri (Günther, 1858) - Fazenda Santa Marta (na lagoa Mangueira) i. 1981; campos da sede da Estação, ii. 1981.

Liophis militaris (L., 1758) - campos da sede da Estação, i, xii. 1979; Fazenda Santa Marta, i, vii. 1980; lagoa Mirim, xii. 1979; recém-nascidos em ninho de roedor, ii. 1980.

Lystrophis dorbignyi (Dumeril, Bibron \& Dumeril, 1854) - Campos da sede da Estação. iii, x, xii. 1980; Fazenda Caçapava, xii. 1979.

Lystrophis histricus (Jan, 1863) - próximo à lagoa das Flores, iv. 1980. Philodryas patagoniensis (Girard, 1857) - Campos da sede da Estação, i. 1979; Fazenda Caçapava, i. 1979; Vila do Taim, iv. 1979; Fazenda Santa Marta, xii. 1979.

Thamnodynastes sp. - Campos da sede da Estação, iii, xii. 1979; vii, xi. 1980; Arroio Sarandi, xii. 1979; margem da lagoa Mirim, i. 1981.

Fam. Crotalidae

Bothrops alternatus Dumeril, Bibron \& Dumeril, 1854 - Área de Albardão, iv. 1979 ; xii. 1980.

Os dados para Thamnodynastes não nos permitem sua classificação ao nível de espécie.

As serpentes foram encontradas em todos os sítios de coleta, exceto sobre as dunas de areia. Sua coleta é feita ao acaso; a maioria dos exemplares foram avistados em nossas buscas pelas zonas de campos; algumas são vistas 
cruzando as pequenas estradas de terra, ou mesmo o asfalto; muitas foram coletadas no terreno da sede da Estação, e duas Thamnodynastes sp. em pequenos córregos superficiais. Um espécime de Liophis jaegeri, que se deslocava na superfície da água na lagoa Mangueira, foi apanhado com uma pequena rede manual.

Segundo os habitantes da região, Bothrops alternatus, a cobra-cruzeira como é chamada, é encontrada freqüentemente em roçados, sendo muito comum na área de Albardão.

Registramos, em março, uma Helicops carinicauda grávida, cum os embriões completamente formados em seu ventre.

\section{Crocodylia}

Segundo informações dos pescadores, os jacarés são encontrados nos pequenos canais que penetram pelo banhado.

Observamos, por vários dias consecutivos, um exemplar de Caiman latirostris (Daudin, 1802), de mais ou menos $1 \mathrm{~m}$ de comprimento, próximo às comportas que controlam o nível de água dos canais; em geral, permanecia com o focinho e por vezes a cabeça toda, ao nível da superfície da água, mergulhando quando nos aproximávamos muito. Uma manhã surpreendemo-lo tomando sol na areia; ao perceber nossa presença escorregou, lateralmente sobre seu ventre, para a água.

\section{COMENTARIOS}

Através do levantamento bibliográficol e exame dos exemplares da coleção do Museu de Zoologia da Universidade de São Paulo, elaboramos uma lista de ocorrência de répteis para o Rio Grande do Sul; e a partir desta, uma chave simplificada que tornou possível o reconhecimento das espécies da Estação Ecológica do Taim.

Tanto o material coletado no Taim, como o que dispúnhamos para comparação, foram insuficientes para um tratamento sistemático. Achamos entretanto que esta lista pode ser publicada como conclusão de uma primeira etapa de trabalho.

Comparando, por número de espécies, os répteis registrados nos Estados do Rio Grande do Sul, com os coletados na Estação do Taim, verificamos que das 81 espécies de ocorrência no Estado, apenas 21 foram encontradas na Estação. Esta percentagem baixa de $26,1 \%$ deve estar diretamente relacionada às condições físicas da região.

Apesar da grande diversidade de ambientes da Estação, estes não parecem ser particularmente favoráveis à presença de répteis. A maior parte da área da Estação é ocupada por banhados, existindo ainda uma larga faixa de areia sem nenhuma vegetação. A presença constante de ventos, mesmo nos meses mais quentes do ano, a ausência quase total de matas, são características que possibilitam a formação de escassos abrigos favoráveis à maioria dos répteis.

Por outro lado, a grande constância de massas de águas, tornam a região privilegiada para tartarugas aquáticas.

\section{AGRADECIMENTOS}

Agradecemos o apoio financeiro recebido do Núcleo Interdepartamental de Ecologia (NIDECO), do Instituto de Biociências da UFRGS através do convênio MINTER-SEMA/NIDECO-UFRGS, e a permissão para utilização da área da Estação Ecológica do Taim.

Ao Dr. Paulo E. Vanzolini, do MZUSP, por empréstimo de bibliografia e classificação da maior parte do material coletado.

1. Deste levantamento, citamos no final do trabalho a bibliografia básica consultada. 
Ao Prof. Bruno Irgang, do Departamento de Botânica, IB, UFRGS, pela determinação das espécies vegetais, depositadas no herbário daquele departamento.

Nosso agradecimento a Léa Marques, estagiária do Departamento de Zoologia, por sua colaboração nos trabalhos de coleta e preparação do material.

\section{REFERENCIAS}

Amaral, A., 1932. Estudos sobre Lacertilios Neotrópicos. I. Novos gêneros e espécies de lagartos no Brasil. Mems Inst. Butantã 7: 51-74.

Boulenger, G. A., 1885. Catalogue of the Lizards in the Bristish Museum, 1: 436 pp.; 2, 497 pp.

Cope, E. D., 1885. Twelfth contribution to the herpetology of the Tropical America. VIII. Rio Grande do Sul, Brazil; H. Smith. Proc. Am. phil. Soc. 22: $167-194$.

Lema, T. de, 1958. Introdução ao estudo dos répteis do Estado do Rio Grande do Sul. Iheringia (Ser. Zool.) 10: 7-18.

Lema, T. de, 1977. Análise geográfica dos répteis do Rio Grande do Sul. Arqos Mus. nac. Rio de J. 54: 61-62.

Lema, T. de, 1973. As serpentes do Estado do Rio Grande do Sul. Iheringia 3: $19-33$.

Lema, T. de \& M. E. Fabian-Beurmann, 1977. Levantamento preliminar dos répteis da região da fronteira Brasil-Uruguai. Iheringia (Ser. Zool.) 50: 61-92.

Luederwaldt, H., 1926. Os chelonios brasileiros, com a lista das espécies do Museu Paulista, Revta Mus. paulista 14: 405-470.

Peters, J. A. \& R. Donoso-Barros, 1970. Catalogue of the Neotropical Squamata. Part II. Lizards and Amphisbaenians. Bull. U. S. natn Mus. 297: viii +293 pp.

Peters, J. A. \& B. Orejas-Miranda, 1970. Catalogue of the Neotropical Squamata. Part I. Snakes. Ibid. 297: viii + 347 pp.

Presch, W., 1973. A review of the Tegus, lizard genus Tupinambis (Sauria, Teiidae) from South America. Copeia 1973 (4): 740-746.

Wermuth, H. \& R. Mertens, 1961. Schildkröten, Krokodile, Brïckenechsen, xxvi + 422 pp. Jena: Gustav Fischer. 